\title{
UK Renal Registry 20th Annual Report: Chapter 4 Demography of the UK Paediatric Renal Replacement Therapy Population in 2016
}

\author{
Lucy Plumb ${ }^{a b}$, Esther Wong ${ }^{a}$, Anna Casula ${ }^{a}$, Fiona Braddon ${ }^{a}$, Malcolm Lewis ${ }^{c}$, \\ Stephen D Marks ${ }^{d}$, Mohan Shenoy ${ }^{e}$, Manish D Sinha ${ }^{f}$, Heather Maxwell ${ }^{\mathrm{g}}$ \\ aUK Renal Registry, Bristol, UK; ' ${ }^{b}$ nniversity of Bristol, Bristol, UK; ' Children's University Hospital, Temple Street, Dublin, \\ Ireland; ${ }^{\mathrm{d}}$ Great Ormond Street Hospital for Children NHS Foundation Trust, London, UK; ${ }^{\mathrm{e}}$ Royal Manchester Children's

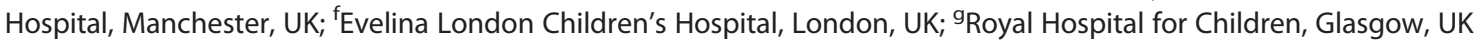

\section{Keywords}

Adolescents · Aetiology · Children · Demography · Established renal failure - Incidence . Prevalence - Pre-emptive transplantation - Renal replacement therapy - Survival . Young adults

\section{Summary}

- In 2016, 964 children and young people aged less than 18 years were receiving long-term renal replacement therapy (RRT) for established renal failure (ERF) at UK paediatric nephrology centres.

- A total of 125 incident patients under 18 years commenced RRT.

- At the census date (31 December 2016), 77\% of prevalent paediatric patients aged $<16$ years had a functioning kidney transplant (43\% live and 34\% deceased donor), $12 \%$ were receiving haemodialysis (HD) and $11 \%$ were receiving peritoneal dialysis (PD).
- In 2016, the prevalence of ERF in patients aged less than 16 years was 64.1 per million age-related population (pmarp). The incidence of ERF for 2016 was 9.0 pmarp.

- Using ERA-EDTA Registry classification, tubulointerstitial disease (which includes congenital/ structural anomalies) accounted for over half of all primary renal diagnoses in prevalent patients, with a high male: female ratio $(3.3: 1)$. Over time, there has been a progressive decline in glomerular disease as a primary renal cause of ERF.

- Between 2002 and 2016, a third of prevalent children in ERF aged three months to 16 years who were referred early received a pre-emptive transplant. Males and White ethnic children were significantly more likely to benefit from pre-emptive transplantation, adjusting for time-period, age at RRT start and primary renal diagnosis.

- At the time of transfer to adult services, $89.4 \%$ of patients had a functioning kidney transplant.

\section{KARGER}

Fax +4161306 1234 E-Mail karger@karger.com www.karger.com/nef
This article is licensed under the Creative Commons AttributionNonCommercial-NoDerivatives 4.0 International License (CC BYNC-ND) (http://www.karger.com/Services/OpenAccessLicense). distribution of modified material requires written permission.
Lucy Plumb

UK Renal Registry, Southmead Hospital, Southmead Road, Bristol, BS10 5NB, UK

Email: renalregistry@renalregistry.nhs.uk 


\section{Introduction}

The UK Renal Registry (UKRR) routinely collects demographic, clinical, haematological and biochemical data for patients receiving long-term renal replacement therapy (RRT) in UK paediatric nephrology centres. In collaboration with the British Association for Paediatric Nephrology (BAPN), this data is analysed and published within the UKRR's annual report.

For UK children and adolescents, RRT for established renal failure (ERF) is managed within one of the thirteen tertiary paediatric nephrology centres. All centres are equipped to provide peritoneal dialysis (PD) and haemodialysis (HD). Ten of these centres also perform kidney transplantation.

Young people aged $16-18$ years may be managed in either paediatric or adult services. This is variable across the UK and dependent on local practices, social factors and patient/family wishes. In this chapter, data for patients aged less than 18 years who are managed within UK paediatric nephrology centres are described, with a focus on those aged less than 16 years, as this group represents a complete cohort. Young people aged 16-18 years who have only ever received nephrology care from adult centres are not included in the analyses.

In the UK in 2015, the prevalence rate of treated ERF in children and adolescents aged $<16$ years was 62.7 per million age-related population (pmarp) and the incidence rate was 10.2 pmarp [1].

The objectives of this chapter are:

1. To describe the UK incidence, prevalence, causes of ERF and modality of treatment of children, adolescents and young adults on RRT on 31 December 2016

2. To describe trends in (1) over the past 15 years

3. To describe pre-emptive transplantation rates and survival of children and adolescents on RRT aged $<16$ years in the UK.

All 13 paediatric nephrology centres in the UK contribute data to the UKRR, mandated in England by the NHS service specification which requires, 'paediatric renal units to submit data comprising the national renal data set to the UK Renal Registry on all patients on renal replacement therapy' [2]. In most cases this is via an annual extract of a centre's clinical computer system which is checked, validated and loaded onto the UKRR paediatric database. At each return, missing data items are sought. Centres pay a capitation fee to support the process. The UKRR is currently moving towards a more streamlined means of data extraction through the UK Renal Data Collaboration (UKRDC), which is due to start receiving and testing extracted 2017 data from renal servers in the summer of 2018.

\section{Methods}

Centres arranged for their own data to be extracted and sent to the UKRR for processing by clinical informaticians. For 2016, all centres were using electronic clinical data capture systems: seven different systems are used among 13 paediatric renal centres. For this report, data returns were required by 31 March 2017. However, data were still received by the UKRR until January 2018.

The content and analyses contained in the paediatric chapters are discussed and agreed by the BAPN Audit and Research Committee members.

In this report, patient groups are described as:

1. 'Incident' group: patients who started RRT between 1 January and 31 December 2016

2. 'Prevalent' group: patients who were receiving RRT on 31 December 2016

3. 'Five-year' groups: patients who started RRT in the periods of 2002-2006, 2007-2011 and 2012-2016.

RRT is defined as all patients with renal transplants and patients on HD and PD for 90 days or more. Dialysis for acute kidney injury (AKI) is not reported currently. All patients $<16$ years of age at the start of RRT are included in these analyses. The cohort of patients starting RRT aged $\geqslant 16$ years of age was incomplete and includes only those whose treatment was started in a paediatric centre.

The populations used to calculate incidence and prevalence were obtained from the Office for National Statistics (ONS) [3]. The mid-2016 population estimate produced by the ONS, based on the 2011 census, was used to calculate the 2016 incidence and prevalence rate; the 2004 population estimate data were used for the 2002-2006 group, the 2009 data for the 2007-2011 group and the 2014 data for the 2012-2016 group. Incidence and prevalence for 16-18-year olds are not reported because data would not be representative of the UK as these young people may also be managed in adult services.

Ethnicity is defined as stated by the patient/family and is reported as White, South Asian, Black and Other. The South Asian ethnicity includes those of Indian, Pakistani or Bangladeshi origin only. The Other ethnicity group includes those from Chinese, other South Asian groups (e.g. Vietnamese, Malaysian), Arabic, mixed race ethnic origin or any other group. Black ethnicity includes those of Black-African, Black-Caribbean origin and Black-other groups.

In previous years, primary renal disease was described according to a registry derived grouping system established in 2002 [4]. For ease of coding and increased comparability, a decision was made to move to 2012 diagnostic groupings used by the ERAEDTA Registry: these include tubulointerstitial disease, glomerular disease, familial and hereditary nephropathies, systemic disease 
affecting the kidney and miscellaneous. Further details on how primary diagnoses are coded and grouped can be found on the ERA-EDTA Registry website (www.era-edta-reg.org/ index.jsp? $\mathrm{p}=37$ ).

Statistical analyses were performed using SAS 9.3, with group analyses using the chi-squared test and median analyses using the Kruskal-Wallis test. Infants under the age of three months and late presenters (defined as those commencing dialysis within three months following first review by a paediatric nephrologist) were excluded from analyses when calculating pre-emptive transplantation rates. Multivariable logistic regression was used to analyse odds of pre-emptive transplantation by age, sex and other demographic variables. For survival analysis, patients starting RRT between 1 January 2002 and 31 December 2015 and receiving RRT for at least 90 days were included to ensure a minimum of one-year follow-up at the census date. These patients were followed up to a maximum age of 16 years, transfer out of paediatric service or death; whichever occurred first. As the maximum age of follow-up was restricted to 16 years it was not possible to calculate 10 -year survival probabilities for patients starting RRT aged over eight years, or five-year survival probability for children starting RRT aged over 12 years. A Cox regression model was used to calculate hazard ratios for patient survival, adjusting for sex, age at start of RRT and RRT modality as a time dependent variable. Survival probabilities were calculated using Kaplan-Meier curves.

\section{Results}

\section{Data returns}

Overall data completeness was excellent for the following: age and sex (100\%), ethnicity (98.7\%), start and 90-day treatment modality $(99.6 \%)$ and start date (99.4\%). Completeness of other data items ranged from $83.5 \%$ to $99.4 \%$ (table 4.1 ). Centre size and type (if undertaking paediatric kidney transplantation) are also displayed. Of note, height at RRT has the lowest level of completeness. While the proportion of missing data is improving over time, lack of height data at RRT start is associated with age, which in part may reflect difficulties in obtaining measurements for very young children $(<2$ years $)$.

The UK paediatric prevalent ERF population in 2016

A total of 964 children and young people aged $<18$ years with ERF were receiving treatment at paediatric nephrology centres in 2016 (table 4.1). Of these, 794 $(82.4 \%)$ were $<16$ years of age. Table 4.2 shows the number of these patients receiving RRT and prevalence rate by age group and sex. More than ten times the number of teenagers received RRT compared with infants. The prevalence of RRT increased with age and was higher in males across all age groups with an overall male to female ratio of $1.7: 1$. The reported prevalence in $<16$ year olds was 64.1 pmarp.

Table 4.3 shows the prevalence of ERF in children less than 16 years old by age and ethnic group. A higher prevalence is again noted for children of ethnic minority. This was particularly evident for South Asian children whose prevalence was almost double the overall RRT prevalence of 64.1 pmarp.

Table 4.1. Data completeness for the paediatric prevalent ERF population on $31 / 12 / 2016$

\begin{tabular}{|c|c|c|c|c|c|c|}
\hline \multirow[b]{2}{*}{ Centre } & \multirow[b]{2}{*}{$N$} & \multicolumn{5}{|c|}{ Percentage completeness } \\
\hline & & $\begin{array}{l}\text { First seen } \\
\text { date }\end{array}$ & $\begin{array}{l}\text { Height at } \\
\text { RRT start }\end{array}$ & $\begin{array}{l}\text { Weight at } \\
\text { RRT start }\end{array}$ & $\begin{array}{c}\text { Creatinine at } \\
\text { RRT start }\end{array}$ & $\begin{array}{c}\text { Primary renal } \\
\text { diagnosis }\end{array}$ \\
\hline Blfst_P* & 30 & 93.3 & 80.0 & 90.0 & 93.3 & 100.0 \\
\hline Bham_P* & 112 & 95.5 & 92.9 & 95.5 & 95.5 & 98.2 \\
\hline Brstl_ ${ }^{*}$ & 55 & 96.4 & 87.3 & 94.6 & 98.2 & 100.0 \\
\hline Cardf_P & 35 & 94.3 & 91.4 & 91.4 & 94.3 & 97.1 \\
\hline Glasg_P* & 60 & 98.3 & 81.7 & 85.0 & 85.0 & 100.0 \\
\hline L Eve_P* & 108 & 86.1 & 68.5 & 75.0 & 74.1 & 99.1 \\
\hline L GOSH_P* & 184 & 96.7 & 87.5 & 94.6 & 94.6 & 100.0 \\
\hline Leeds_P* & 81 & 100.0 & 88.9 & 100.0 & 100.0 & 100.0 \\
\hline Livpl_P & 55 & 98.2 & 78.2 & 83.6 & 92.7 & 100.0 \\
\hline Manch_P* & 88 & 96.6 & 95.5 & 97.7 & 97.7 & 100.0 \\
\hline Newc_P* & 32 & 96.9 & 90.6 & 90.6 & 81.3 & 100.0 \\
\hline Nottm_P* & 94 & 95.7 & 75.5 & 95.7 & 96.8 & 97.9 \\
\hline Soton_P & 30 & 93.3 & 46.7 & 46.7 & 56.7 & 100.0 \\
\hline UK & 964 & 95.4 & 83.5 & 90.3 & 91.2 & 99.4 \\
\hline
\end{tabular}

RRT - renal replacement therapy

*Denotes centres undertaking kidney transplantation for children 
Table 4.2. The UK paediatric prevalent ERF population $<16$ years old on $31 / 12 / 2016$, by age group and sex

\begin{tabular}{|c|c|c|c|c|c|c|c|}
\hline \multirow[b]{2}{*}{ Age group (years) } & \multicolumn{2}{|c|}{ All patients } & \multicolumn{2}{|c|}{ Males } & \multicolumn{2}{|c|}{ Females } & \multirow{2}{*}{$\begin{array}{c}\mathrm{M}: \mathrm{F} \text { rate } \\
\quad \text { ratio }\end{array}$} \\
\hline & $N$ & pmarp & $N$ & pmarp & $N$ & pmarp & \\
\hline $0-<2$ & 24 & 15.3 & 16 & 19.9 & 8 & 10.5 & 1.9 \\
\hline $2-<4$ & 59 & 36.7 & 43 & 52.2 & 16 & 20.4 & 2.6 \\
\hline $4-<8$ & 177 & 53.9 & 121 & 72.0 & 56 & 34.9 & 2.1 \\
\hline $8-<12$ & 233 & 75.3 & 142 & 89.5 & 91 & 60.3 & 1.5 \\
\hline $12-<16$ & 301 & 106.2 & 190 & 130.9 & 111 & 80.3 & 1.6 \\
\hline Under 16 & 794 & 64.1 & 512 & 80.7 & 282 & 46.7 & 1.7 \\
\hline
\end{tabular}

pmarp - per million age related population

Table 4.3. The UK paediatric prevalent ERF population $<16$ years old in 2016 , by age and ethnic group ${ }^{\text {a }}$

\begin{tabular}{|c|c|c|c|c|}
\hline Age group (years) & White & South Asian & Black & Other \\
\hline $0-<4$ & 53 & 12 & 5 & 9 \\
\hline $4-<8$ & 126 & 21 & 5 & 22 \\
\hline $8-<12$ & 157 & 47 & 10 & 15 \\
\hline $12-<16$ & 220 & 48 & 15 & 16 \\
\hline Under 16 & 556 & 128 & 35 & 62 \\
\hline pmarp $(<16)^{\mathrm{b}}$ & 55.6 & 120.6 & 64.6 & 78.4 \\
\hline
\end{tabular}

pmarp - per million age related population

${ }^{a}$ Ethnicity not recorded for 13 children, not included in this table

${ }^{b}$ pmarp was calculated by assuming the same ethnic distribution for $<16$ years old from the 2011 ONS census, applied to the total UK 2016 population aged $<16$ years old

\section{Treatment modality}

Most prevalent paediatric patients under 16 years old in 2016 had a functioning transplant (77\%), as shown in figure 4.1. The ratio of living to deceased donor transplants was $1: 0.8$.

By comparison, $45 \%$ of patients started RRT on $\mathrm{PD}$, $33 \%$ on $\mathrm{HD}$ and $22 \%$ with a pre-emptive transplant, as displayed in figure 4.2.

Analysis of current treatment modality by age shows that the majority of patients below the age of four years

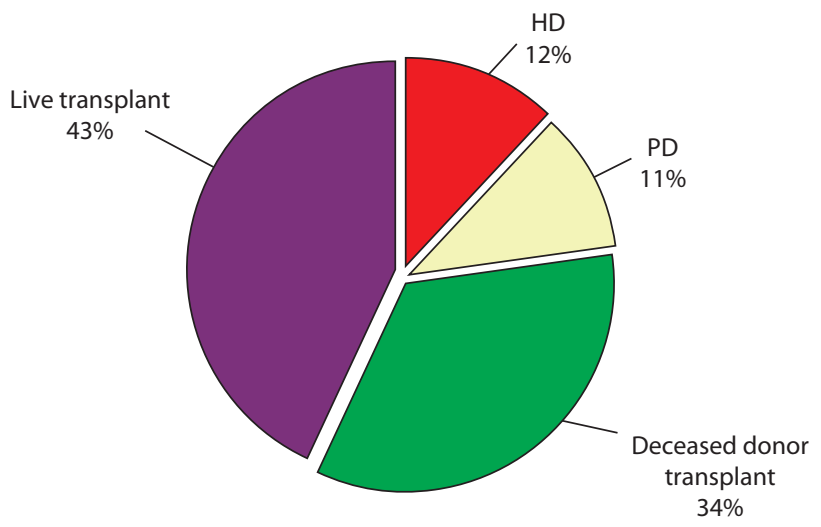

Fig. 4.1. RRT treatment used by prevalent paediatric patients $<16$ years old on $31 / 12 / 2016$ were receiving dialysis whilst most children over four years had a transplant (table 4.4). Transplantation was not performed in any child under two years of age and living donor transplants were more common than deceased donor transplants in those aged two to twelve years. When comparing current treatment by ethnicity in 2016, White children were more likely to have a functioning transplant compared with non-White children $(p=0.003)$. This finding however was not age-adjusted which given the higher proportion of ethnic minorities

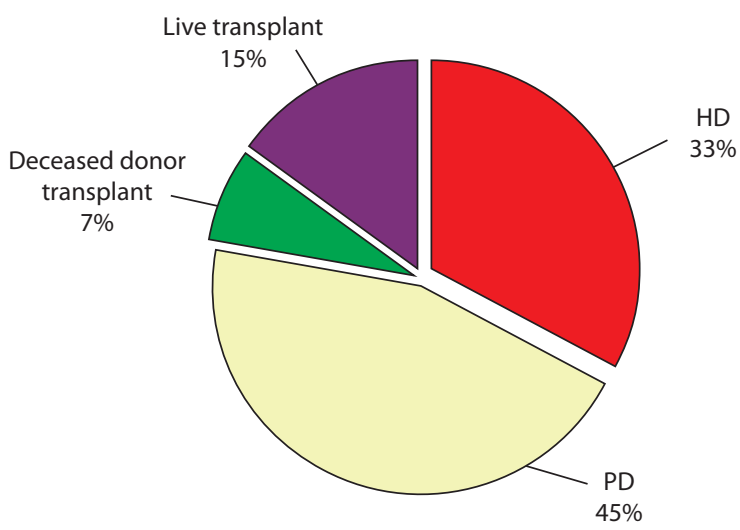

Fig. 4.2. Treatment modality at start of RRT in prevalent paediatric patients $<16$ years old on $31 / 12 / 2016$

Plumb/Wong/Casula/Braddon/Lewis/ Marks/Shenoy/Sinha/Maxwell 
Table 4.4. Current treatment modality by age group in the UK paediatric prevalent ERF population $<18$ years old on $31 / 12 / 2016$

\begin{tabular}{|c|c|c|c|c|c|c|c|c|c|}
\hline \multirow{3}{*}{$\begin{array}{l}\text { Age group } \\
\text { (years) }\end{array}$} & \multirow[b]{3}{*}{ Total $N$} & \multicolumn{8}{|c|}{ Current treatment } \\
\hline & & \multicolumn{2}{|c|}{ HD } & \multicolumn{2}{|c|}{ PD } & \multicolumn{2}{|c|}{ Live transplant } & \multicolumn{2}{|c|}{ Deceased donor transplant } \\
\hline & & $N$ & $\%$ & $N$ & $\%$ & $N$ & $\%$ & $N$ & $\%$ \\
\hline $0-<2$ & 24 & 7 & 29.2 & 17 & 70.8 & 0 & 0.0 & 0 & 0.0 \\
\hline $2-<4$ & 59 & 19 & 32.2 & 24 & 40.7 & 11 & 18.6 & 5 & 8.5 \\
\hline $4-<8$ & 177 & 19 & 10.7 & 17 & 9.6 & 98 & 55.4 & 43 & 24.3 \\
\hline $8-<12$ & 233 & 26 & 11.2 & 10 & 4.3 & 113 & 48.5 & 84 & 36.1 \\
\hline $12-<16$ & 301 & 23 & 7.6 & 22 & 7.3 & 122 & 40.5 & 134 & 44.5 \\
\hline $16-<18$ & 170 & 14 & 8.2 & 11 & 6.5 & 68 & 40.0 & 77 & 45.3 \\
\hline Under 16 & 794 & 94 & 11.8 & 90 & 11.3 & 344 & 43.3 & 266 & 33.5 \\
\hline Under 18 & 964 & 108 & 11.2 & 101 & 10.5 & 412 & 42.7 & 343 & 35.6 \\
\hline
\end{tabular}

HD - haemodialysis; PD - peritoneal dialysis

Table 4.5. Number and percentage of the prevalent ERF population $<16$ years old in 2016 , by sex and ethnicity

\begin{tabular}{|c|c|c|c|c|c|}
\hline Tubulointerstitial disease & 424 & 53.4 & 326 & 98 & 26.9 \\
\hline Glomerular disease & 134 & 16.9 & 65 & 69 & 30.8 \\
\hline Systemic diseases affecting the kidney & 34 & 4.3 & 18 & 16 & 12.1 \\
\hline Miscellaneous & 78 & 9.8 & 45 & 33 & 26.7 \\
\hline Missing & 6 & 0.8 & 5 & 1 & 20.0 \\
\hline
\end{tabular}

aged under four years, may partly explain the differences seen (data not shown).

\section{Cause of ERF}

Tubulointerstitial disease (TID) was the commonest renal diagnostic group in prevalent patients under 16 years in 2016 (table 4.5), accounting for over half of all primary renal disease (PRD) diagnoses. The high male to female ratio for this group $(3.33: 1)$ likely reflects the number of boys with obstructive uropathy due to posterior urethral valves. Based on previous reporting criteria, congenital anomalies of the kidneys and urinary tract (CAKUT) account for almost all the diagnoses within this group (99.8\%, data not shown). Congenital nephrotic syndrome accounted for $60 \%$ of prevalent glomerular disease requiring RRT (81 patients). In 2016, there were 21 prevalent patients receiving RRT due to malignancy, whilst no patients had a PRD of drug toxicity (both now coded under 'miscellaneous'). Primary renal disease was uncertain or unknown in only $4 \%$ of patients.

Overall, White patients constituted $71.2 \%$ of the prevalent ERF population, but represented $87.9 \%$ of patients with systemic diseases affecting the kidney. This diagnostic group encompasses conditions such as haemolytic uraemic syndrome (HUS) and renovascular disease. Prevalent and incident PRD data by historic UKRR groupings are available for comparison (figure 4.6 and table 4.13 in appendix 1 of this chapter).

Figure 4.3 displays the proportion of patients in each ERA-EDTA diagnostic category for the incident and prevalent cohorts.

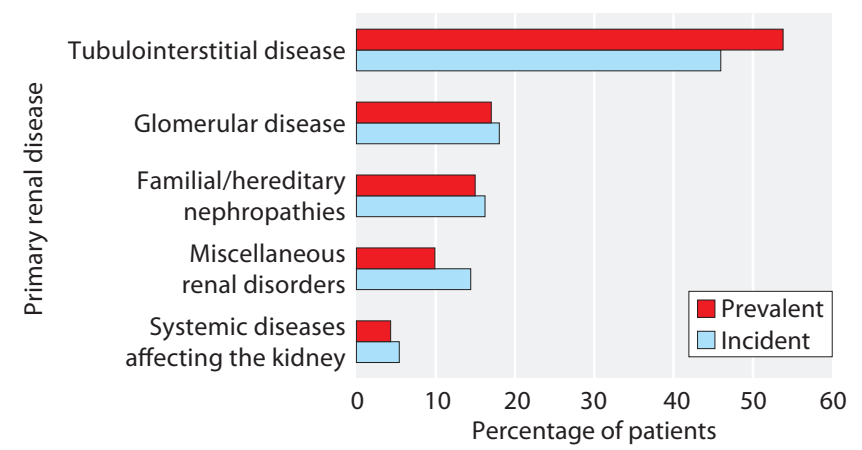

Fig. 4.3. Comparison of PRD groupings in the 2016 UK paediatric incident and prevalent ERF population $<16$ years old for patients with non-missing data 
Table 4.6. The UK paediatric incident ERF population $<16$ years old in 2016 , by age group and sex

\begin{tabular}{|c|c|c|c|c|c|c|}
\hline \multirow[b]{2}{*}{ Age group (years) } & \multicolumn{2}{|c|}{ All patients } & \multicolumn{2}{|c|}{ Males } & \multicolumn{2}{|c|}{ Females } \\
\hline & $N$ & pmarp & $N$ & pmarp & $N$ & pmarp \\
\hline $0-<2$ & 24 & 15.3 & 14 & 17.4 & 10 & 13.1 \\
\hline $2-<4$ & 8 & 5.0 & 7 & 8.5 & 1 & 1.3 \\
\hline $4-<8$ & 17 & 5.2 & 12 & 7.1 & 5 & 3.1 \\
\hline $8-<12$ & 25 & 8.1 & 15 & 9.5 & 10 & 6.6 \\
\hline $12-<16$ & 38 & 13.4 & 17 & 11.7 & 21 & 15.2 \\
\hline Under 16 & 112 & 9.0 & 65 & 10.2 & 47 & 7.8 \\
\hline
\end{tabular}

pmarp - per million age related population

The UK paediatric incident ERF population in 2016

There were 125 patients $<18$ years of age who commenced RRT at paediatric renal centres in 2016. The following analyses are restricted to the 112 patients who were $<16$ years of age.

The overall incidence of RRT was 9.0 pmarp in 2016. Patients commencing RRT in 2016 are displayed by age and sex in table 4.6; apparent differences may be a result of small group sizes.

\section{Trends in ERF demographics}

There were 1,720 children and adolescents $<16$ years of age who received RRT in the UK between 2002 and 2016. In general, the overall incidence of RRT has remained steady over the past ten years (table 4.7). Relative increases in incidence were seen in younger patients, notably the under two and two to four year age groups, while a decrease was seen for children aged 12 to $<16$ years. Table 4.8 shows a decrease in the

Table 4.7. Reported numbers and average incidence by age group in five-year time periods of the UK paediatric incident ERF population $<16$ years old commencing RRT

\begin{tabular}{|c|c|c|c|c|c|c|}
\hline \multirow[b]{2}{*}{ Age group (years) } & \multicolumn{2}{|c|}{$2002-2006$} & \multicolumn{2}{|c|}{ 2007-2011 } & \multicolumn{2}{|c|}{ 2012-2016 } \\
\hline & $N$ & pmarp & $N$ & pmarp & $N$ & pmarp \\
\hline $0-<2$ & 77 & 11.1 & 100 & 12.7 & 112 & 14.2 \\
\hline $2-<4$ & 33 & 4.9 & 59 & 7.8 & 75 & 9.1 \\
\hline $4-<8$ & 89 & 6.2 & 89 & 6.4 & 113 & 7.1 \\
\hline $8-<12$ & 109 & 7.3 & 129 & 9.0 & 136 & 9.4 \\
\hline $12-<16$ & 210 & 13.4 & 213 & 14.0 & 176 & 12.3 \\
\hline Under 16 & 518 & 8.8 & 590 & 10.0 & 612 & 10.1 \\
\hline
\end{tabular}

pmarp - per million age related population

Table 4.8. Number* and percentage of the UK paediatric incident ERF population $<16$ years old who commenced RRT, by ethnicity and five-year period of starting RRT

\begin{tabular}{|c|c|c|c|c|c|c|}
\hline \multirow[b]{2}{*}{ Ethnic group } & \multicolumn{2}{|c|}{$2002-2006$} & \multicolumn{2}{|c|}{ 2007-2011 } & \multicolumn{2}{|c|}{ 2012-2016 } \\
\hline & $N$ & $\%$ & $N$ & $\%$ & $N$ & $\%$ \\
\hline White & 409 & 79.4 & 432 & 74.1 & 411 & 68.6 \\
\hline South Asian & 77 & 15.0 & 95 & 16.3 & 104 & 17.4 \\
\hline Black & 14 & 2.7 & 27 & 4.6 & 23 & 3.8 \\
\hline Other & 15 & 2.9 & 29 & 5.0 & 61 & 10.2 \\
\hline Under 16 & 515 & & 583 & & 599 & \\
\hline
\end{tabular}

*Three children in 2002-2006, seven in 2007-2011 and 13 in 2012-2016 with no ethnicity recorded are excluded from this table 
Table 4.9. Number and percentage of the UK paediatric incident ERF population $<16$ years old, by renal centre and five-year period of starting RRT

\begin{tabular}{|c|c|c|c|c|c|c|}
\hline \multirow[b]{2}{*}{ Centre } & \multicolumn{2}{|c|}{ 2002-2006 } & \multicolumn{2}{|c|}{$2007-2011$} & \multicolumn{2}{|c|}{ 2012-2016 } \\
\hline & $N$ & $\%$ & $N$ & $\%$ & $N$ & $\%$ \\
\hline Blfst_P & 14 & 2.7 & 26 & 4.4 & 15 & 2.5 \\
\hline Bham_P & 54 & 10.4 & 61 & 10.3 & 71 & 11.6 \\
\hline Brstl_ $\bar{P}$ & 35 & 6.8 & 35 & 5.9 & 31 & 5.1 \\
\hline Cardf_P & 20 & 3.9 & 15 & 2.5 & 24 & 3.9 \\
\hline Glasg_P & 30 & 5.8 & 47 & 8.0 & 38 & 6.2 \\
\hline L Eve_P & 43 & 8.3 & 70 & 11.9 & 69 & 11.3 \\
\hline L GOSH_P & 101 & 19.5 & 114 & 19.3 & 111 & 18.1 \\
\hline Leeds_P & 51 & 9.8 & 47 & 8.0 & 55 & 9.0 \\
\hline Livpl_P & 30 & 5.8 & 22 & 3.7 & 34 & 5.6 \\
\hline Manch_P & 50 & 9.7 & 46 & 7.8 & 66 & 10.8 \\
\hline Newc_P & 26 & 5.0 & 25 & 4.2 & 25 & 4.1 \\
\hline Nottm_P & 46 & 8.9 & 62 & 10.5 & 58 & 9.5 \\
\hline Soton_P & 18 & 3.5 & 20 & 3.4 & 15 & 2.5 \\
\hline Under 16 & 518 & & 590 & & 612 & \\
\hline
\end{tabular}

proportion of White ethnic and an increase in Other ethnic group patients starting RRT over the same time periods. Table 4.9 shows that the overall proportions between paediatric renal centres have fluctuated only slightly over this period.

The proportion of patients starting RRT with deceased donor transplants fell (from 13.4\% in 2002-2006 to 7.7\% in 2012-2016, figure 4.4) with total numbers down by $30 \%$ over this time. Living donor transplantation as a start modality has seen small increases during this period. The proportion of PD use at RRT start continued to fall, having dropped from $48.5 \%$ in $2002-2006$ to $37.9 \%$ in 2012-2016. This reduction is offset mainly by increased

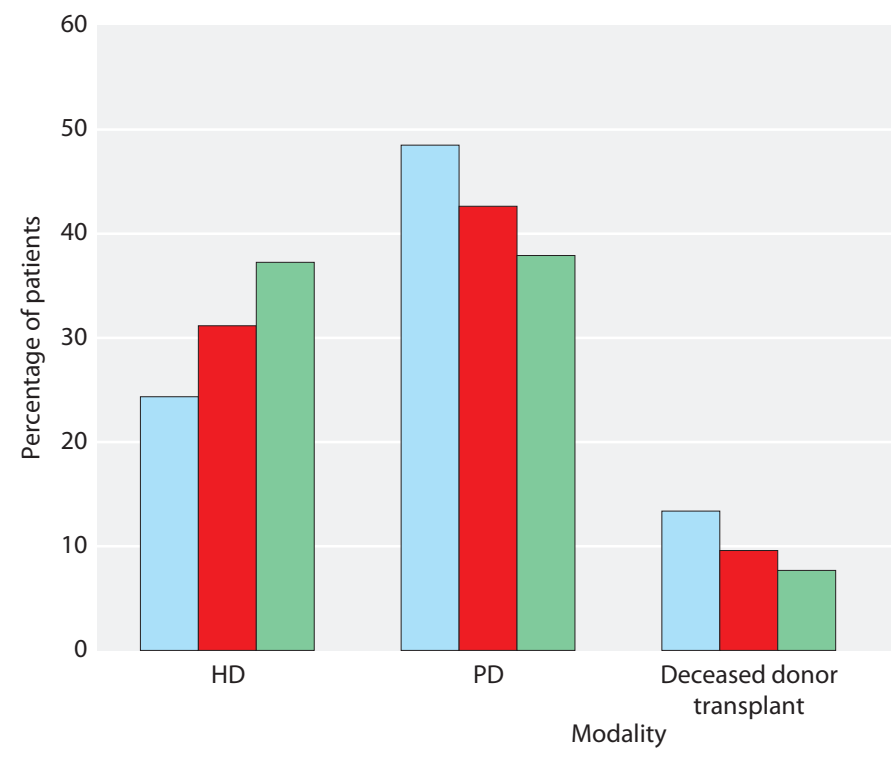

use of $\mathrm{HD}$, with patient numbers having almost doubled since 2002-2006 (122 to 228 patients).

The proportion of patients with glomerular disease as a cause of ERF in the prevalent paediatric population has fallen over the last 15 years (table 4.10). Numbers of incident patients commencing chronic RRT for congenital nephrotic syndrome over this time period however have almost doubled (see appendix 1, table 4.13).

\section{Pre-emptive transplantation}

Of the 1,720 patients aged $<16$ years who started RRT between 2002 and 2016, 454 were excluded from this analysis (94 patients due to being aged under three
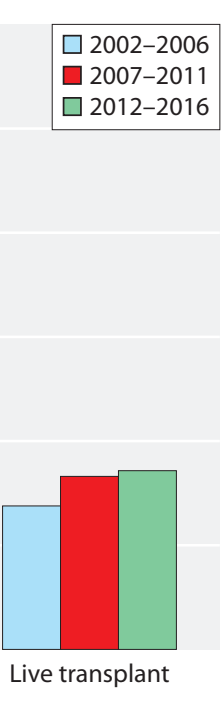

Fig. 4.4. Treatment modality at start of RRT for the UK paediatric incident ERF population $<16$ years old, by five-year time-period 
Table 4.10. Number* and percentage of primary renal diseases in the UK paediatric prevalent ERF population $<16$ years old, by five-year time-period

\begin{tabular}{|c|c|c|c|c|c|c|c|}
\hline \multirow[b]{2}{*}{ Primary renal diagnosis } & \multicolumn{2}{|c|}{$2002-2006$} & \multicolumn{2}{|c|}{$2007-2011$} & \multicolumn{2}{|c|}{ 2012-2016 } & \multirow{2}{*}{ 2002-2016 } \\
\hline & $N$ & $\%$ & $N$ & $\%$ & $N$ & $\%$ & \\
\hline Glomerular disease & 116 & 22.6 & 115 & 19.7 & 104 & 17.1 & -5.5 \\
\hline Familial/hereditary nephropathies & 78 & 15.2 & 102 & 17.5 & 98 & 16.1 & 0.9 \\
\hline Systemic diseases affecting the kidney & 14 & 2.7 & 34 & 5.8 & 22 & 3.6 & 0.9 \\
\hline
\end{tabular}

*Five children in 2002-2006, six in 2007-2011 and five in 2012-2016 with no primary renal diagnosis recorded are excluded from this table

months, 360 due to being late presenters). Table 4.11 shows that one third of included patients $(N=1,266)$ received a pre-emptive transplant.

A significant difference exists in pre-emptive transplantation rates by sex, with higher rates seen in boys $(p=0.001)$; this difference persisted $(p=0.002)$ when adjusted for time-period, ethnicity, age at RRT start and PRD in a logistic regression. Significantly higher rates were also seen in White patients (versus nonWhite ethnicity, $p=<0.0001$ ). As expected, fewer preemptive transplantations were performed in very young patients $(<2$ years). When children under two years were excluded from analysis, a significant difference in pre-emptive transplantation rates between age groups persisted $(p=0.02)$, however this was not significant when assuming a linear correlation with age $(p=0.2)$ using the Mantel-Haenszel test.

Pre-emptive transplantation rates differed by PRD according to ERA-EDTA registry groupings ( $p=$ 0.0001 ); the lowest rates were seen in patients with glomerular or miscellaneous disease.

\section{Transfer of patients to adult renal services in 2016}

Ninety patients transitioned to adult renal services in 2016, similar to the 85 who transferred during 2015. The median age of patients at transfer was 18.0 years with an inter-quartile range of 17.7-18.3 years. Overall, the demographics of this population reflected those of the prevalent paediatric RRT population, but with a higher proportion having a functioning transplant $(89.4 \%$ versus $77.0 \%)$.

\section{Survival of children on RRT during childhood}

Of patients under 16 years of age, 1,575 started RRT between 2002 and 2015 at paediatric centres in the UK and were included in survival analyses. At the census date (31 December 2016) there were 75 deaths reported in children aged $<16$ years, which is the same number as for 2015. The median follow up time (beyond day 90) was 3.3 years (range three days to 14.6 years). Table 4.12 shows the survival hazard ratios by age at start of RRT, sex and RRT modality and highlights that very young children $(<2$ years $)$ at RRT start had the worst survival outcomes, when compared to 12-16 year olds. Being on dialysis has again shown to lower survival

Table 4.11. Demographic characteristics of pre-emptive transplantation in the UK paediatric ERF population aged three months to 16 years, 2002-2016, by five-year time-period, sex, ethnicity, age at start of RRT and PRD

\begin{tabular}{|c|c|c|}
\hline Characteristic & $N$ & $\begin{array}{c}N(\%) \\
\text { pre-emptively } \\
\text { transplanted }\end{array}$ \\
\hline Total cohort analysed (2002-2016) & 1,266 & $423(33.4)$ \\
\hline $\begin{array}{l}\text { Time period } \\
2002-2006 \\
2007-2011 \\
2012-2016\end{array}$ & $\begin{array}{l}393 \\
410 \\
463\end{array}$ & $\begin{array}{l}130(33.1) \\
144(35.1) \\
149(32.2)\end{array}$ \\
\hline $\begin{array}{l}\text { Sex } \\
\text { Male } \\
\text { Female }\end{array}$ & $\begin{array}{l}797 \\
469\end{array}$ & $\begin{array}{l}287(36.0) \\
136(29.0)\end{array}$ \\
\hline $\begin{array}{l}\text { Ethnicity } \\
\text { White } \\
\text { South Asian } \\
\text { Other } \\
\text { Black }\end{array}$ & $\begin{array}{r}918 \\
207 \\
76 \\
45\end{array}$ & $\begin{array}{r}337(36.7) \\
48(23.2) \\
24(31.6) \\
7(15.6)\end{array}$ \\
\hline $\begin{array}{l}\text { Age at start of RRT (years) } \\
3 \text { months }-<2 \\
2-<4 \\
4-<8 \\
8-<12 \\
12-<16\end{array}$ & $\begin{array}{l}141 \\
144 \\
232 \\
291 \\
458\end{array}$ & $\begin{aligned} 8 & (5.7) \\
39 & (27.1) \\
99 & (42.7) \\
103 & (35.4) \\
172 & (38.0)\end{aligned}$ \\
\hline $\begin{array}{l}\text { Primary renal diagnosis } \\
\text { Tubulointerstitial disease } \\
\text { Glomerular disease } \\
\text { Familial/hereditary nephropathies } \\
\text { Miscellaneous renal disorders } \\
\text { Systemic diseases affecting the kidney }\end{array}$ & $\begin{array}{r}678 \\
245 \\
195 \\
91 \\
44\end{array}$ & $\begin{aligned} 295 & (43.5) \\
19 & (7.8) \\
65 & (33.3) \\
24 & (26.4) \\
17 & (38.6)\end{aligned}$ \\
\hline
\end{tabular}


Table 4.12. Survival hazard ratio during childhood for the UK paediatric ERF population $<16$ years old, for age at start of RRT, sex and RRT modality

\begin{tabular}{lccc}
\hline Characteristic & $\begin{array}{c}\text { Hazard } \\
\text { ratio }\end{array}$ & $\begin{array}{c}\text { Confidence } \\
\text { interval }\end{array}$ & p-value \\
\hline Age & & & \\
$\quad 0-<2$ years & 3.0 & $1.3-6.9$ & 0.012 \\
$2-<4$ years & 2.0 & $0.7-5.4$ & 0.18 \\
$4-<8$ years & 2.2 & $0.9-5.5$ & 0.08 \\
$\quad 8-<12$ years & 1.0 & $0.3-2.7$ & 0.9 \\
12-<16 years & 1.0 & & \\
Sex & & & \\
Female & 1.1 & $0.7-1.7$ & 0.7 \\
Male & 1.0 & & \\
RRT modality & & & \\
Dialysis & 7.4 & $3.9-14.1$ & $<0.0001$ \\
Transplant & 1.0 & & \\
\hline
\end{tabular}

significantly compared to having a functioning transplant, with a hazard ratio of 7.4 (CI 3.9-14.1, $p<0.0001)$. Figure 4.5 shows unadjusted Kaplan-Meier survival probabilities and demonstrates worse outcomes for children aged less than two years, particularly in the first 12 months. By comparison, children and young people aged 8-16 years have very good one year survival rates, with no deaths reported.

\section{Mortality data in 2016}

Ten deaths occurred in children under 16 years in 2016; the median age at death was 7.7 years (range 0.415.5 years). In children aged $<16$ years with treated ERF, the reported mortality in UK paediatric centres was $1.3 \%(10 / 794)$.

\section{Transplant deaths}

One patient had a functioning kidney transplant at time of death. The cause of death was unexplained.

\section{Dialysis deaths}

In 2016, six patients were on dialysis at time of death (three PD, three HD). One patient died of malignancy, one of pancreatitis, two of septicaemia and another due to cardiac failure secondary to a metabolic disorder. Cause of death was not established in one patient. Three further patients had dialysis withdrawn due to medical (non-renal) reasons.

\section{Discussion}

This report continues to provide important insights into the demography of UK children and young people on long-term RRT with comparison of trends over time. Information gleaned from the registry is not only vital for planning and financing tertiary services but has the potential to facilitate translation of research into clinical practice, thus driving improvements in patient care [5]. Moreover, moving towards a more standardised method of coding for primary renal disease, further comparisons with international registries will be possible.

\section{Data returns}

One of the key aims of the UKRR is to provide contemporaneous epidemiological data on the paediatric RRT cohort. This is dependent on centres submitting data to the UKRR in a timely fashion, thus allowing

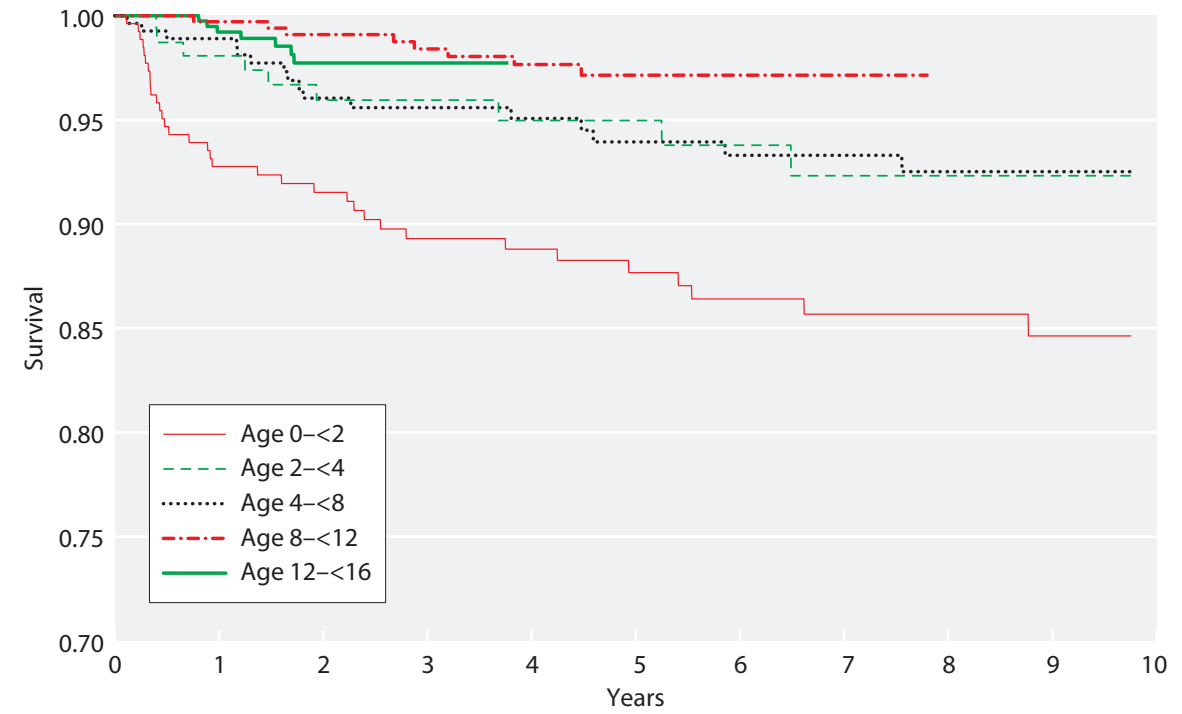

Fig. 4.5. Unadjusted Kaplan-Meier survival in the UK paediatric ERF population $<16$ years old starting RRT between 2002 and 2015, by age at start 
thorough data checks and validation to occur prior to analysis.

For the paediatric dataset, this process has its own inherent challenges and limitations. Firstly, some renal computer systems extract adult and paediatric data together despite differences in the data fields requested, which results in requests for additional paediatric data from centres. Secondly, important missing data fields that have not been automatically populated by local systems require contact with lead clinicians in each centre to 'fill in the gaps'. Understandably, this can cause a delay in data cleaning and validation while placing an additional burden on busy clinical teams. Suggestions on how to improve and streamline this process are welcomed.

\section{Highlights from the 2016 data}

Overall, there has been little change in the reported age-adjusted prevalence and incidence of the paediatric RRT population. Teenagers account for a high proportion of the prevalent population, although their incidence remained stable over time. Conversely, children under two years accounted for a small proportion of the prevalent population in 2016 (3\%), yet incident numbers starting chronic RRT were increasing year-on-year. Based on 2016 population census figures, ethnic minorities continued to record a high prevalence of patients on RRT, with South Asian ethnicity accounting for the highest.

Most prevalent patients had a functioning transplant which is encouraging, further still was the high proportion of young people transitioning to adult care dialysis-free $(89.4 \%)$. As expected, high proportions of younger children $(<4$ years) were reliant on dialysis, with few receiving a kidney transplant.

As reported in the last audit, less than a quarter of UK children commencing RRT received a pre-emptive transplant, with disparities seen amongst the sexes and ethnic groups despite adjusting for potential confounders. Sex differences in paediatric access to transplantation echo findings reported by the ERA-EDTA Renal Registry: females were $23 \%$ less likely than males to receive a pre-emptive transplant with medical factors explaining only $70 \%$ of the variation seen [6]. This analysis was unable to account for non-clinical characteristics such as socio-economic status (SES). In addition, the US Renal Data System has reported reduced access to living donor pre-emptive transplantation in ethnic minorities, with black patients $66 \%$ and Hispanics 52\% less likely to benefit from pre-emptive transplantation, despite adjustment for SES [7]. An analysis of UKRR data to explore whether SES is associated with access to pre- emptive transplantation has been approved and is planned for this coming year.

\section{RRT start modality}

PD remained the most popular start modality in 2016, used in just under half of all patients commencing RRT. Over time however, its use and that of deceased donor transplantation is falling, with concurrent increases in HD use seen. When analysed by time-period, the numbers of patients starting on HD and PD for 20122016 were similar (228 versus 232 respectively). Whilst living donor transplantation is increasing over time, the reason for the noticeable increases in $\mathrm{HD}$ use (over PD or deceased donor transplantation) is unclear and requires further investigation.

\section{Primary renal disease}

This year, the UKRR paediatric dataset has moved to the 2012 ERA-EDTA diagnostic grouping system to categorise primary renal disease. However, reference to previous UKRR groupings is made. Tubulointerstitial disease, which encompasses structural and congenital anomalies, accounts for over half of all prevalent cases of ERF.

Numbers of patients with glomerular disease as a primary cause for ERF is falling over time. As the UKRR expands to collect data on patients with earlier pre-dialysis stages of CKD (4 and 5), understanding will increase as to whether this observation is due to improved disease control or a true reduction in disease leading to glomerular pathology. It is also noted that fewer patients with glomerular or miscellaneous disease are pre-emptively transplanted. As these groupings may encompass disease processes with a rapid decline in function (miscellaneous includes codes for acute kidney injury), this may preclude patients from early transplantation.

\section{Comorbidity}

Reporting of comorbidities in the paediatric RRT population has been challenging for some time. Data completeness remained low and recorded comorbidity varied greatly between centres. This has led to concerns regarding the representativeness of the burden of disease faced by the paediatric nephrology community. In view of this, and in eager anticipation of findings from the 20162017 BAPN comorbidities audit, it was decided that UKRR collated information would not be included in this year's report. Furthermore, research is planned that aims to compare and validate UKRR recorded 
comorbidity with Hospital Episode Statistics (HES) data, thus enhancing our knowledge of this cohort.

\section{Survival}

Survival data from the UKRR continued to show the negative effect of younger age on mortality risk and medium-term survival compared with older age groups. Dialysis use also confers substantial mortality risk. A recent UK publication describing survival of young people aged 11-30 years reinforces these findings and highlights that this risk is further amplified for patients who are not wait-listed for transplant (HR 16.6, 95\% CI 10.8-25.4, $p=<0.0001$ ) [8]. Although few paediatric deaths are reported each year, it is becoming apparent that cause of death, often due to a complex interaction between renal and extra-renal factors, in many cases is not fully captured by a single code-reporting system. A BAPN-UKRR audit of RRT deaths is planned this year to ascertain how best to collect and report this data for audit and research purposes.

\section{Current and future work}

Several paediatric based projects are underway or planned in collaboration with the UK Renal Registry this coming year. It is encouraging to note that of the submitted applications to the UKRR for data in 2017-2018, half are paediatric based or include a paediatric element.

Several projects have been developed jointly with the BAPN. The need for improved comorbidity reporting in the RRT cohort has led to the development and completion of a UK-wide survey by paediatric nephrology centres. Results have now been received by the UKRR, with a report of findings expected later this year.

Another BAPN-UKRR project is planned for later this year which will audit cause of death data for RRT patients with paediatric centre-held medical records. As previously described, the aims of this project are to 1) understand risk factors for death by age and disease group and 2) determine whether current coding systems accurately capture cause of death for the paediatric population.

As the UKRR expands its dataset to include patients under pre-dialysis care, little is known about children who develop ERF but in whom a decision is made not to pursue renal replacement therapy. It is not clear whether these children are known to nephrology services, what factors are implicated in the decision for conservative management, or whether decisions regarding lifesustaining treatment are made in accordance with national and international guidance. An initial proposal to explore this issue in greater detail has been submitted and approved by the British Paediatric Surveillance Unit (BPSU). It is hoped this prospective study will provide a more accurate picture of childhood ERF in the UK and will also inform future data collection through the UKRR.

Approved paediatric/young adult research projects using UKRR data include an analysis of risk factors implicated in graft survival and rate of function decline posttransplantation; exploring the association of non-clinical variables in timing and access to specialist services and an analysis of the benefits of transplant versus dialysis for children using a marginal structural modelling approach. A follow-up report on children who commenced dialysis aged less than two years is also planned.

Applications are welcomed for paediatric and young adult research projects using UKRR data. Further details regarding the application process can be found on the UKRR website: www.renalreg.org/about-us/workingwith-us/.

Conflicts of interest: the authors declare no conflicts of interest

\section{References}

1 Hamilton AJ, Braddon F, Casula A, Inward C, Lewis M, Mallett T, Maxwell H, O’Brien C, Tse Y, Sinha MD. UK Renal Registry 18th Annual Report: Chapter 4 Demography of Patients Receiving Renal Replacement Therapy in Paediatric Centres in the UK in 2014. Nephron. 2016; 132 (suppl 1):99-110. doi: 10.1159/000444818

2 NHS England. 2013/14 NHS Standard Contract for Paediatric Medicine: Renal. Particulars, Schedule 2 - The Services, A - Service Specification http://www.england.nhs.uk/wp-content/uploads/2013/06/e03-paedi-medirenal.pdf

3 https://www.ons.gov.uk/census

4 Ansell D, Ansell D, Feest T, Byrne C. The UK Renal Registry: The Fifth Annual Report. UK Renal Registry; 2002

5 Plumb LA, Hamilton AJ, Inward CD, Ben-Shlomo Y, Caskey FJ. Continually improving standards of care: The UK Renal Registry as a translational public health tool. Pediatric Nephrology. 2017 Jun 22:1-8.

6 Hogan J, Couchoud C, Bonthuis M, Groothoff JW, Jager KJ, Schaefer F, Van Stralen KJ. Gender Disparities in Access to Pediatric Renal Transplantation in Europe: Data From the ESPN/ERA-EDTA Registry. American Journal of Transplantation. 2016 Jul 1;16(7):2097-105

7 Patzer RE, Sayed BA, Kutner N, McClellan WM, Amaral S. Racial and ethnic differences in pediatric access to preemptive kidney transplantation in the United States. American Journal of Transplantation. 2013 Jul 1;13(7):1769-81

8 Hamilton AJ, Casula A, Ben-Shlomo Y, FJ Caskey, CD Inward. The clinical epidemiology of young people starting renal replacement therapy in the UK: presentation, management and survival using 15 years of UK Renal Registry data. Nephrology Dialysis Transplantation 2018 Feb 1; 33(2): 356-364 


\section{Appendix 1: Historic UKRR diagnostic groupings}

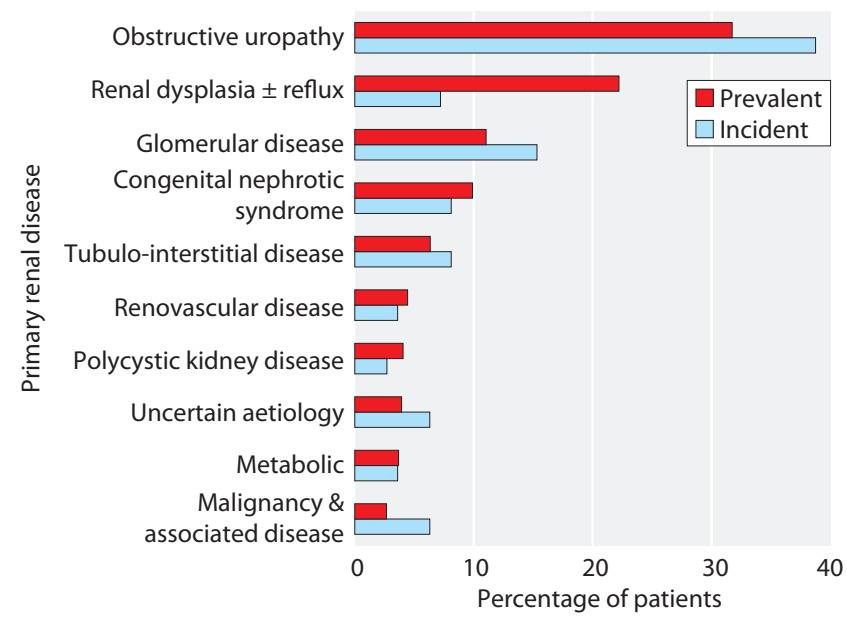

Fig. 4.6. Proportion of primary renal disease by historic UKRR diagnostic groupings in incident and prevalent paediatric patients in 2016 for whom a causative diagnosis was reported

Table 4.13. Number and percentage of children under 16 years for whom a primary renal diagnosis had been reported as a cause of ERF (using historic UKRR groupings), by 5 -year time period

\begin{tabular}{|c|c|c|c|c|c|c|}
\hline \multirow[b]{2}{*}{ Primary renal diagnosis } & \multicolumn{2}{|c|}{ 2002-2006 } & \multicolumn{2}{|c|}{ 2007-2011 } & \multicolumn{2}{|c|}{ 2012-2016 } \\
\hline & $N$ & $\%$ & $N$ & $\%$ & $N$ & $\%$ \\
\hline Congenital nephrotic syndrome & 25 & 4.9 & 35 & 6.0 & 49 & 8.1 \\
\hline Glomerular disease & 103 & 20.1 & 118 & 20.2 & 74 & 12.2 \\
\hline Polycystic kidney disease & 15 & 2.9 & 19 & 3.3 & 22 & 3.6 \\
\hline Metabolic & 21 & 4.1 & 31 & 5.3 & 28 & 4.6 \\
\hline Obstructive uropathy & 83 & 16.2 & 95 & 16.3 & 204 & 33.6 \\
\hline Renal dysplasia + reflux & 168 & 32.7 & 181 & 31.0 & 105 & 17.3 \\
\hline Tubulo-interstitial diseases & 42 & 8.2 & 49 & 8.4 & 44 & 7.2 \\
\hline Malignancy \& associated disease & 11 & 2.1 & 6 & 1.0 & 16 & 2.6 \\
\hline Uncertain aetiology & 26 & 5.1 & 25 & 4.3 & 41 & 6.8 \\
\hline Drug nephrotoxicity & 6 & 1.2 & 3 & 0.5 & 0 & 0.0 \\
\hline Renovascular disease & 13 & 2.5 & 22 & 3.8 & 24 & 4.0 \\
\hline Total & 513 & & 584 & & 607 & \\
\hline
\end{tabular}

